\title{
Does CDX2 expression predict Barrett's metaplasia in oesophageal columnar epithelium without goblet cells?
}

\author{
M. KERKHOF*, D. A. BAX*, L. M. G. MOONS*, A. J. VAN VUUREN*, H. VAN DEKKEN†, \\ E. W. STEYERBERG $\#$, E. J. KUIPERS*, J. G. KUSTERS* \& P. D. SIERSEMA*, FOR THE CYBAR STUDY \\ GROUP ${ }^{1}$
}

Departments of *Gastroenterology and Hepatology; †Pathology and †Public Health, Erasmus MC - University Medical Center Rotterdam, Rotterdam, The Netherlands

Correspondence to:

Dr P.D. Siersema, Department of Gastroenterology and Hepatology, Erasmus MC - University Medical Center Rotterdam, P0 Box 2040, 3000 CA Rotterdam, The Netherlands.

E-mail: p.siersema@erasmusmc.nl

${ }^{1}$ Participating investigators and centres are listed in the Appendix

\section{Publication data}

Submitted 23 August 2006

First decision 14 September 2006

Resubmitted 20 September 2006

Accepted 20 September 2006

\section{SUMMARY}

\section{Background}

Intestinal metaplasia (Barrett's oesophagus), but not cardiac-type mucosa in columnar-lined oesophagus, is regarded as premalignant. As intestinal metaplasia and cardiac-type mucosa are endoscopically indiscernible, it is difficult to take targeted samples from columnar-lined oesophagus with consequently a risk of having undetected intestinal metaplasia.

\section{Aim}

To investigate whether the intestinal markers CDX2, MUC2 and villin can predict the presence of undetected intestinal metaplasia in columnar-lined oesophagus.

\section{Methods}

Presence of intestinal metaplasia or cardiac-type mucosa was identified in 122 biopsy sets of columnar-lined oesophagus from 61 patients, collected at two subsequent follow-up upper endoscopies. CDX2, MUC2 and villin expression were determined by immunohistochemistry.

\section{Results}

All intestinal metaplasia samples (55) were positive for CDX2 and MUC2 and 32 of 55 for villin. CDX2 expression was detected in 23 of 67 (34\%) samples with only cardiac-type mucosa. Detection of CDX2 in cardiac-type mucosa increased the likelihood of finding intestinal metaplasia in another biopsy set of columnar-lined oesophagus (odds ratio $3.5,95 \% \mathrm{CI}=1.2-10, P=0.02$ ). MUC2 was positive in 13 of 23 (57\%) of CDX2-positive cardiac-type mucosa samples, whereas villin was detected in seven of 23 (30\%).

\section{Conclusions}

CDX2 expression in cardiac-type mucosa might be able to predict the presence of undetected intestinal metaplasia in columnar-lined oesophagus, and thus may be a putative marker for the presence of intestinal metaplasia in the absence of goblet cells.

Aliment Pharmacol Ther 24, 1613-1621 


\section{INTRODUCTION}

Barrett's oesophagus (BO) is a premalignant condition caused by chronic gastro-oesophageal reflux, ${ }^{1}$ which can progress from low-grade dysplasia to high-grade dysplasia, and subsequently to oesophageal adenocarcinoma. $^{2-5}$

Barrett's oesophagus is characterized by the replacement of the squamous epithelium of the oesophagus by columnar epithelium with goblet cells [specialized intestinal metaplasia (IM)]. ${ }^{6}$ IM is associated with the expression of intestinal markers such as MUC2, ${ }^{7}$ and villin. ${ }^{8}$ Cardiac-type mucosa (CM) is also frequently observed in the columnar-lined oesophagus (CLO), ${ }^{9}$ with the absence of goblet cells as the only histological difference compared with IM. ${ }^{10} \mathrm{CM}$, in contrast to IM, is not regarded as a premalignant condition. ${ }^{5,11}$ Therefore, only patients with IM are currently advised to undergo periodic endoscopic surveillance to detect progression to dysplasia in an early, potentially curable stage. ${ }^{12}$ Others have reported that patients with biopsies from CLO without IM were at an increased risk of having undetected IM. This was explained by either sampling error or developing IM over time. According to current guidelines, these patients would have been falsely excluded from a surveillance programme. ${ }^{13}$

The homeobox protein CDX2 is a transcription factor involved in the early intestinal differentiation of the epithelium of the intestines, ${ }^{14-16}$ and its expression is also linked with $\mathrm{BO},{ }^{17-19}$ suggesting that CDX2 is an early marker for the development of IM in the oesophagus as well. CDX2 regulates transcription of several intestinal genes, encoding proteins such as MUC2, alkaline phosphatase and sucrase-isomaltase. $^{20,21}$ It has been reported that intestinal phenotypic modifications may also be detected in the absence of goblet cells by CDX2 expression in CLO. $^{22,23}$ This epithelium has been regarded as being early-stage B0, but these studies were cross-sectional and therefore provided not enough evidence for this hypothesis.

The aim of this longitudinal study was to investigate whether intestinal markers for IM, i.e. CDX2 (early intestinal marker), MUC2 (goblet cell marker) and villin (late intestinal marker), were present in the columnar-lined segment of the oesophagus in the absence of a histological diagnosis of IM (defined by the presence of goblet cells). Furthermore, we investigated whether these markers were predictive for the presence of IM in CLO, not detected due to sampling error or to IM developing over time.

\section{MATERIALS AND METHODS}

\section{Patients and materials}

In this multicentre study, 108 patients were evaluated for this retrospective study for the presence of an endoscopic CLO of at least $2 \mathrm{~cm}$, and at least two follow-up endoscopies with biopsies being performed. Based on these inclusion criteria, 47 patients were excluded, and consequently 61 patients could be included in this study. Biopsies were taken at different levels from the CLO and embedded together in one paraffin block. In this study, sections of these paraffinembedded biopsy sets were used for evaluation. These slides were reviewed for the presence of IM by an expert gastrointestinal pathologist (HvD). Based on the presence of IM, patients were divided into three groups (Table 1): patients with IM in both biopsy sets (IM-group), patients with IM in one biopsy set and with only CM in the other biopsy set (discordantgroup), and patients with only CM in both biopsy sets (CM-group). Patients with CM in the first endoscopy and IM in the second endoscopy, and visa versa, were taken together as the discordant-group.

\section{Histology and immunohistochemistry}

Six consecutive sections of $4 \mu \mathrm{m}$ each from every biopsy set were mounted on adhesive slides, dried overnight at $37^{\circ} \mathrm{C}$, and deparaffinized with xylene. The first of these serially sectioned slides was stained with haematoxylin and eosin (H\&E) to determine the type of columnar epithelium (CM or IM). Alcian Blue and periodic acid-Schiff (PAS) stainings in consecutive

Table 1. Classification of patients in groups, based on histology results from two subsequent endoscopies

\begin{tabular}{lllll}
\hline & IM-group & $\begin{array}{l}\text { Discordant- } \\
\text { group }\end{array}$ & CM-group \\
\hline $\begin{array}{llll}\text { First endoscopy } \\
\begin{array}{l}\text { Second } \\
\text { endoscopy }\end{array}\end{array}$ & IM & IM & CM & CM \\
$\begin{array}{l}\text { No. of patients } \\
\text { IM }\end{array}$ & 15 & CM & IM & CM \\
\hline
\end{tabular}

IM, intestinal metaplasia; CM, cardiac-type mucosa. 
slides were performed to facilitate the detection of mucin producing goblet cells. The next three slides were used for immunohistochemistry.

For immunohistochemistry, antigen retrieval was performed by boiling the deparaffinized samples in $10 \mathrm{~mm}$ monocitric acid buffer (pH 6.0) for $15 \mathrm{~min}$, and slowly cooling down to room temperature (RT). Prior to immune staining, endogenous peroxidase activity was blocked by incubating the slides in a $0.5 \%$ solution of $\mathrm{H}_{2} \mathrm{O}_{2}$ in phosphate-buffered citric acid for $15 \mathrm{~min}$ at RT. Samples were washed for $5 \mathrm{~min}$ with TRIS-buffered saline (TBS) (pH 7.4). This was repeated two times. The samples were incubated in TBS buffer containing 10\% rabbit non-immune serum (Dako, Glostrup, Denmark) and 10\% normal human plasma (Dako) for $20 \mathrm{~min}$. Sections were incubated for $16 \mathrm{~h}$ at $4{ }^{\circ} \mathrm{C}$ with respectively primary antibody anti-CDX2 (clone 392M; Biogenex, San Ramon CA, USA) in a 1:100 dilution, anti-MUC2 (clone Ccp58; Novocastra, Newcastle upon Tyne, UK) in a 1:100 dilution or antivillin (clone CWWB1; Lab Vision, Fremont CA, USA) in a 1:2000 dilution. Samples were again washed three times for 5 min with TBS (pH 7.4). Subsequently, biotin-labelled rabbit-anti-mouse antibody (Dako) was used as second antibody, followed by the addition of a streptavidin-horseradish peroxidase complex (Dako) using 3-amino-9-ethylcarbazole as substrate. Slides were analysed for nuclear CDX2 staining, cytoplasmic MUC2 staining and brush border villin staining by two independent investigators (MK, DAB) who were blinded for the presence or absence of IM. CDX2 expression was considered positive if a clear red staining of at least five adjacent nuclei in the same gland was seen, to exclude incidental false positive nuclei. MUC2 expression was present if a red staining in the cytoplasm of (goblet) cells was observed. Villin expression was visualized as a red staining near the apical border of cells.

\section{Statistical analysis}

The chi-squared test, Mann-Whitney test and KruskalWallis test were used to compare the patient characteristics and the immunohistochemical stainings between the three patient groups. A $P$-value $<0.05$ was considered significant. Odds ratios (ORs) with a 95\% confidence interval were used as an estimate of the relative risk for the presence of IM. Calculations were initially done with upper endoscopies as the unit of analysis, ignoring the statistical dependency of endoscopies within the same patients. Subsequently, analyses were repeated with the consideration of only one endoscopy per patient. Statistic analyses were conducted using SPSS software (SPSS version 11.0; SPSS, Chicago, IL, USA).

\section{RESULTS}

\section{The presence of IM}

Intestinal metaplasia was defined as the presence of goblet cell containing glands. In addition to goblet cells, non-goblet cells can also stain positive with alcian blue. Therefore, the presence of IM was evaluated by light-microscopic examination of HEtE stained slides. Consecutive alcian blue and PAS stained slides were only used to confirm a diagnosis of IM.

Intestinal metaplasia was observed in 55 of 122 (45\%) biopsy sets. In 67 of 122 (55\%) biopsy sets, only $\mathrm{CM}$ was present. The mean number of biopsies taken was five in the IM-group and four in the discordantand CM-group (similar at the two endoscopies in each group), which was not significantly different (Table 2). When correcting for the length of the columnar segment, the mean number of biopsies taken per centimetre was not different in IM and CM biopsy sets (respectively 1.5/cm (range 0.1-4.3) and 1.5/cm (range 0.3-4.0), $P=0.68$ ). Based on the presence of IM, the IM-group consisted of 15 patients, the discordantgroup of 25 patients, and the CM-group of 21 patients. Of all patient characteristics, only the length of the CLO differed significantly between the three groups $(P=$ 0.016), with CLO being longer in the IM-group, compared with the discordant- and the CM-group (Table 2).

\section{CDX2 expression}

To investigate the expression of CDX2 protein in IM and $\mathrm{CM}, \mathrm{CDX} 2$ staining was evaluated. CDX2 expression was observed in all IM-positive biopsy sets (Table 3; Figure 1a,b), i.e. in 30 of the IM-group and in 25 of the discordant-group. In addition, CDX2 expression was also observed in 23 of 67 (34\%, 95\% CI: 2347) biopsy sets without IM (Table 3; Figure 1c,d).

CDX2 was more frequently observed in IM-negative biopsy sets of patients of the discordant-group, in which the other biopsy set was positive for IM (13/25; $52 \%)$, than in patients of the CM-group, in which IM was absent in both biopsy sets $(10 / 42 ; 24 \%)(P=$ 0.019). The presence of $\mathrm{CDX} 2$ in $\mathrm{CM}$ therefore 
Table 2. Patients characteristics

IM-group $\quad$ Discordant-group $\quad \mathrm{CM}$-group $\quad P$-value

No. of patients

Mean age at first endoscopy in years (range)

Mean length of the CLO in cm (range)

Mean number of biopsies (range)

Interval between subsequent endoscopies in months (range)

Proton-pump inhibitor use (\%)

$\begin{array}{rr}15 & 25 \\ 59 & (28-82) \\ 4(2-8)^{*} & 58(39-78) \\ 5(1-17) & 3(2-7) \\ 42(12-158) & 31(1-7) \\ 11 / 13(85 \%) & 20 / 22(91 \%)\end{array}$

21

$52(27-74) \quad 0.30$

$3(2-5) \quad 0.016$

4 (1-8) $\quad 0.27$

$30(4-117) \quad 0.54$

$12 / 19(63 \%) \quad 0.18$

IM, intestinal metaplasia; CM, cardiac-type mucosa; CLO, columnar-lined oesophagus.

* Significantly different.

Table 3. Results of immunohistochemical stainings of all biopsy sets

\begin{tabular}{|c|c|c|c|c|c|c|}
\hline \multirow[b]{2}{*}{ Group (no. pts) } & \multicolumn{3}{|l|}{ IM } & \multicolumn{3}{|l|}{ CM } \\
\hline & IM (30) & Discordant (25) & Total (55) & Discordant (25) & CM (42) & Total (67) \\
\hline CDX2-positive & $30(100 \%)$ & $25(100 \%)$ & $55(100 \%)$ & $13(52 \%)^{* *}$ & $10(24 \%)$ & $23(34 \%)$ \\
\hline MUC2-positive & 30 (100\%) & $25(100 \%)$ & 55 (100\%) & $11(44 \%)$ & $5(12 \%)$ & $16(24 \%)$ \\
\hline Villin-positive & $22(73 \%)$ & $10(40 \%)$ & $32(58 \%)$ & $4(17 \%)^{*}$ & $3(7 \%)$ & $7(10 \%)$ \\
\hline
\end{tabular}

significantly increased the likelihood of observing IM in another biopsy set of the CLO (OR 3.5, 95\% CI: 1.2$10, P=0.021$ ), regardless if CM in the discordant-group was present in biopsies from the first or second upper endoscopy. When we calculated the predictive value of CDX2 expression in biopsies with CM taken during the first endoscopy, for the presence of IM in biopsies of the next endoscopy, and visa versa, the ORs were similar (respectively 4.0, 95\% CI: $0.8-21, P=0.10$ and 3.2, 95\% CI: $0.8-13, P=0.10$ ). In one patient of group 3 , both IM-negative biopsies were positive for CDX2.

A longer segment of CLO was not associated with a higher change of $\mathrm{CDX} 2$ being present in $\mathrm{CM}(P=$ 0.135). There was no correlation between the use of proton-pump inhibitors and the presence of CDX2 in CM $(P=0.42)$.

\section{MUC2 expression}

Mucins are large glycoproteins forming the main components of the gel-like mucous layer on the sur- face of the intestine, protecting the mucosa against damaging luminal contents, such the gastro-oesophageal refluxate. ${ }^{24}$ MUC2 is a mucin specific for IM. $^{25-27}$ As CDX2 regulates the transcription of MUC2 ${ }^{21}$ we evaluated the expression of MUC2 in IM and CM. MUC2 staining in goblet cells was found in all biopsy sets with IM (Table 3, Figure 2a), and was mainly localized in the cytoplasm alongside the membrane. Moreover, MUC2 was also expressed in CM in 16 of 67 (24\%) samples without IM. In CM, MUC2 was expressed in the entire cytoplasm of nongoblet columnar cells that did not stain positive with alcian blue (Figure 2b). Thirteen of 16 (81\%) MUC2positive CM samples were also positive for CDX2 in the same region.

\section{Villin expression}

Villin is an actin-binding cytoskeletal protein essential for brush border formation (microvilli) in normal end-differentiated epithelial cells of the intestine. ${ }^{28}$ 

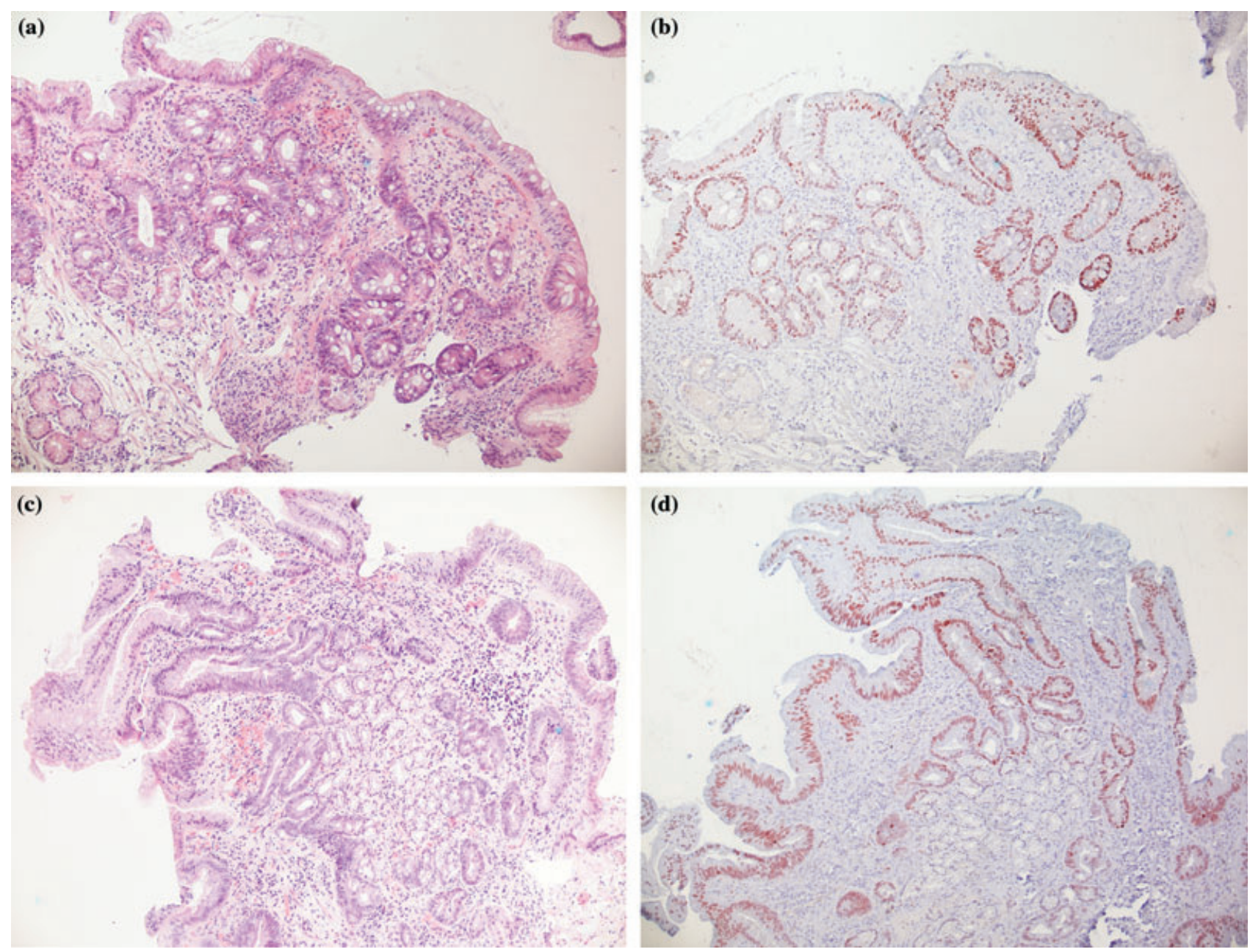

Figure 1. CDX2 expression in columnar epithelium of the oesophagus. (a) Intestinal-type columnar epithelium with goblet cells (haematoxylin-eosin). (b) Nuclear staining (red) for CDX2 in intestinal-type columnar epithelium in a serial section of the same patient as in (a). (c) Cardiac-type columnar epithelium without goblet cells (haematoxylin-eosin). (d) CDX2 expression in cardiac-type columnar epithelium in a serial section of the same patient as in (c). Original magnifications $\times 100$.

Therefore, the presence of a brush border of the oesophageal columnar epithelium can be demonstrated by villin expression. We investigated whether villin protein was also expressed in $\mathrm{CM}$ in addition to the intestinal markers CDX2 and MUC2. One CM sample could not be evaluated, as there was not enough tissue available for staining. Villin expression was observed in 32 of 55 (58\%) of IM-positive biopsy sets (Figure 3a). In seven of 66 (11\%) CM samples, villin expression was found (Figure 3b), of which five were also CDX2 positive. Four CM samples (6\%) were positive for CDX2 and MUC2, as well as for villin.

\section{DISCUSSION}

Patients with CM in CLO are currently excluded from surveillance endoscopy, as they are regarded as IM negative and thus as not having a premalignant condition. $^{13}$ This study shows a significant relationship between the intestinal marker CDX2 in CM and the presence of IM in biopsies taken at another time point, as CDX2 stained positive in 52\% of CM biopsy sets of the discordant-group (with an OR of 3.5), in which the biopsy set of the other endoscopy was positive for IM (Table 2). In our opinion it is unlikely that, despite the two-dimensional analysis of the biopsies, goblet cells 
(a)

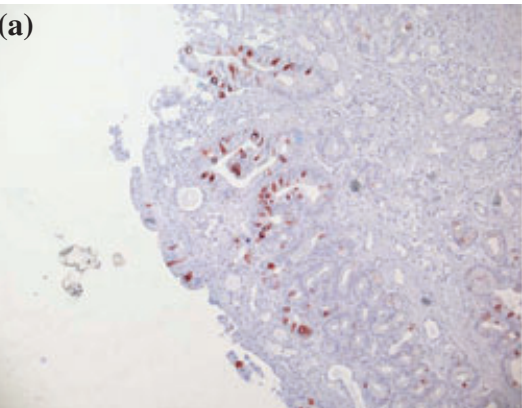

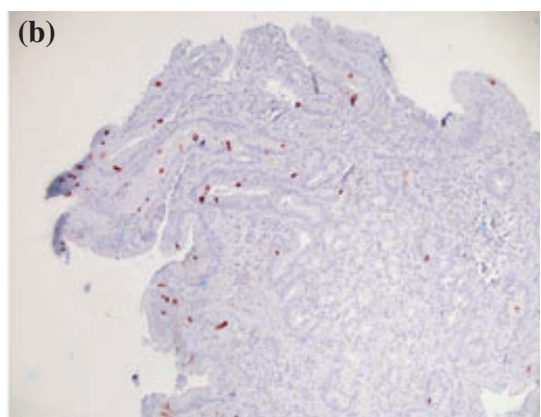

Figure 2. MUC2 expression in columnar epithelium of the oesophagus. (a) MUC2 staining in goblet cells (red) in intestinaltype columnar epithelium. (b) MUC2 expression in cardiac-type columnar epithelium without goblet cells in a serial section of the same patient as in Figure 1c. Note that the MUC2 expression is not associated with goblet cells. Original magnifications $\times 100$.
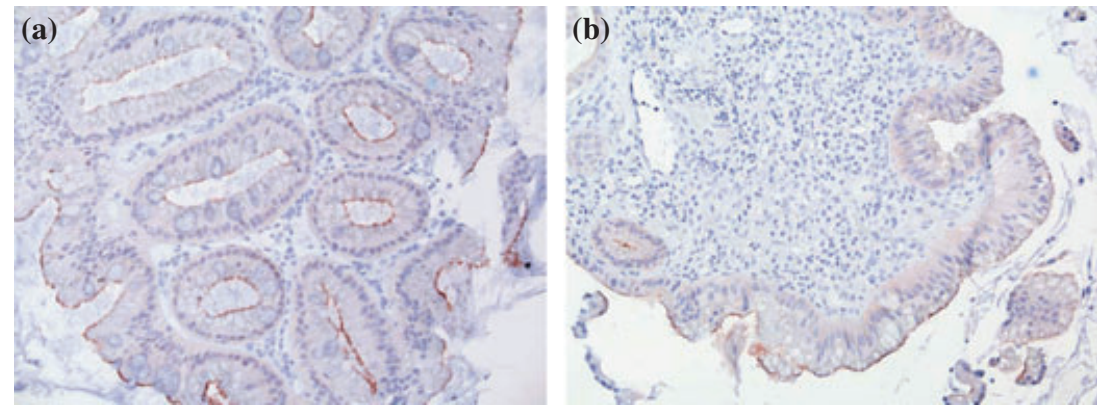

Figure 3. Villin expression in columnar epithelium of the oesophagus. (a) Villin staining of the brush border (red) in intestinal-type columnar epithelium. (b) Villin expression in cardiac-type columnar epithelium without goblet cells. Note that the villin expression is not associated with goblet cells. Original magnifications $\times 200$.

have been missed in these CM biopsy sets, as the CDX2 expression was often observed in large areas without goblet cells (Figure 1c,d), and, in addition, in the six consecutive slides also no goblet cells were observed. Therefore, CDX2 staining may represent a useful histological marker for the presence of IM in CLO despite the absence of goblet cells suggestive for IM.

CDX2 expression in CM as an indicator for the presence of IM has been reported in previous studies. ${ }^{19,2}$ These studies were however cross-sectional, which means that biopsies were only evaluated at one timepoint. In contrast, this study was a longitudinal study, in which biopsy sets of two subsequent endoscopies were compared.

Previously, it has been suggested that there are two possible reasons for not detecting IM. ${ }^{13}$ First, several authors have proposed that IM may develop over time in a two-step process. It has been suggested that multilayered epithelium, with morphological and immunohistochemical characteristics of both squamous and columnar epithelium, may represent a transitional stage in the development of BO. ${ }^{29}$ Others have suggested that IM develops from previously induced $\mathrm{CM}$ in the oesophagus under influence of chronic inflammation. ${ }^{13,30-32}$ According to this theory, the finding of CDX2 expression in CM, and in a subset also expression of MUC2 and villin, could indicate early intestinal differentiation prior to morphologic changes such as goblet cells, ${ }^{19,33}$ and in this way being an intermediate stage in the differential shift of CM towards IM. ${ }^{28,} 30$

The second possibility for not detecting IM is sampling error. Although IM is predominantly present in the proximal end of the CLO, ${ }^{34}$ IM and CM may have a patchy distribution. As IM and CM are endoscopically indiscernible from each other, and the presence of IM can be very focal, ${ }^{35}$ sampling error for the detection 
of IM may occur. ${ }^{13}$ Sixteen of the 25 patients of the discordant-group had IM in their first, and CM in their second biopsy set (Table 1). It seems likely that in these cases the finding of no IM can be contributed to sampling error. The likelihood of detecting IM increased with the number of biopsies taken, and therefore taking not enough biopsies could be a reasonable explanation for missing IM in this group. As in this study the mean number of biopsies taken per $\mathrm{cm}$ was similar in the IM samples and the CM samples, the possibility of sampling error seems to be ruled out. However, as IM has a patchy appearance in the CLO but is predominantly located at the proximal end of the $\mathrm{CLO},{ }^{12,}, 34$ it is possible that despite taking the same numbers of biopsies, IM could be missed due to taking proportionally less biopsies of the proximal part of the CLO. A similar explanation can be given for the other nine patients of the discordant-group who had CM detected at their first endoscopy, whereas IM was found in biopsies from the second endoscopy. As the mean interval between two subsequent endoscopies in the discordant-group was with 30 months relatively long, and the development of IM is thought to be a slow process, it is also possible that IM in this subgroup has developed over time.

Although a final conclusion on the cause of not detecting IM in one set of biopsies cannot be given, the ORs for the predicting value of CDX2 in CM in the different subgroups were similar, and thus it is reasonable to assume that CDX2 expression in CM represents a reliable marker for the detection of the premalignant IM in CLO at another time point. In line with this assumption, it is likely that the $24 \%$ with CDX2 expression in CM biopsy sets in whom IM was not detected in both biopsy sets taken at different time points, will show IM in biopsies taken at a next endoscopy. Unfortunately, because of exclusion from the surveillance programme, these patients have currently not undergone another follow-up upper endoscopy to evaluate this.

CDX2 is a transcription factor for MUC2, which is a mucin specific for IM. ${ }^{25-27}$ In our study, as expected, all IM biopsies stained positive for MUC2. In 13 of 23 (57\%) of the CDX2-positive CM biopsies, MUC2 staining was also positive. Villin expression was observed in 58\% of the IM-positive samples. This lower result of villin expression in IM compared with CDX2 expression and MUC2 expression has been suggested to be caused by the fact that the quantity of villin protein needs to have a sufficient level to result in a mature brush border. ${ }^{36,37}$ In addition to villin expression in IM, five of $23(22 \%)$ of the CDX2-positive CM samples also showed villin expression, suggesting the presence of end-differentiated intestinal characteristics in CM. Although less frequent, the presences of MUC2 and villin expression in $\mathrm{CM}$ are supportive for the value of CDX2 as indicator of IM in CLO.

A possible limitation of this study is the use of one single technique to detect CDX2 in the biopsies. The major reason that we only used immunohistochemistry was that additional techniques such RT-PCR, ${ }^{18}$ could not be performed on our paraffin-embedded tissue, but only on fresh snap frozen biopsies, which were not available in this retrospective study. However, as we performed the CDX2 immunohistochemical stainings with a commonly used dilution, ${ }^{17}, 18$ which showed only very specific nuclear staining without background staining in the cytoplasm of cells, it is unlikely that the immunohistochemistry may have resulted in false positive results.

In conclusion, this study shows that the presence of CDX2 in CM might be able to predict the presence of IM in CLO, which was otherwise not detected because of sampling error or developing of IM over time. This suggests that CDX2 staining could be used as an additional marker for the presence of IM in CLO in the absence of goblet cells. A prospective follow-up study on patients with $\mathrm{CM}$ in their biopsies should be performed to confirm the predictive value of CDX2. Nonetheless, as the presence of IM is still the gold standard for the presence of premalignant BO, we suggest an additional endoscopy in patients in whom CDX2 expression in CM is demonstrated. This should include the taking of extensive biopsies for the detection of IM (especially near the squamo-columnar junction) to evaluate if endoscopic surveillance is indeed indicated in these patients.

\section{CONFLICTS OF INTEREST}

We declare that we have no conflict of interest.

\section{ACKNOWLEDGEMENTS}

This work was supported by a grant of the Health Care Efficiency Research Program - Effects \& Costs (ZonMW Doelmatigheidsonderzoek; project no.: 94503-035, the CYBAR study). 


\section{REFERENCES}

1 Avidan B, Sonnenberg A, Schnell TG, et al. Hiatal hernia size, Barrett's length, and severity of acid reflux are all risk factors for esophageal adenocarcinoma. Am J Gastroenterol 2002; 97: 1930-6.

2 Buttar NS, Wang KK. Mechanisms of disease: carcinogenesis in Barrett's esophagus. Nat Clin Pract Gastroenterol Hepatol 2004; 1: 106-12.

3 Haggitt RC. Barrett's esophagus, dysplasia, and adenocarcinoma. Hum Pathol 1994; 25: 982-93.

4 Hameeteman W, Tytgat GN, Houthoff HJ, van den Tweel JG. Barrett's esophagus: development of dysplasia and adenocarcinoma. Gastroenterology 1989; 96: 1249-56.

5 Hamilton SR, Smith RR. The relationship between columnar epithelial dysplasia and invasive adenocarcinoma arising in Barrett's esophagus. Am J Clin Pathol 1987; 87: 301-12.

6 Guillem PG. How to make a Barrett esophagus: pathophysiology of columnar metaplasia of the esophagus. Dig Dis Sci 2005; 50: 415-24.

7 Chinyama CN, Marshall RE, Owen WJ, et al. Expression of MUC1 and MUC2 mucin gene products in Barrett's metaplasia, dysplasia and adenocarcinoma: an immunopathological study with clinical correlation. Histopathology 1999; 35: 517-24.

8 Regalado SP, Nambu Y, Iannettoni MD, Orringer MB, Beer DG. Abundant expression of the intestinal protein villin in Barrett's metaplasia and esophageal adenocarcinomas. Mol Carcinog 1998; 22: 182-9.

9 Paull A, Trier JS, Dalton MD, et al. The histologic spectrum of Barrett's esophagus. $N$ Engl J Med 1976; 295: 476-80.

10 Chandrasoma PT, Lokuhetty DM, Demeester TR, et al. Definition of histopathologic changes in gastroesophageal reflux disease. Am J Surg Pathol 2000; 24: 344-51.

11 Falk GW. Barrett's esophagus. Gastroenterology 2002; 122: 1569-91.

12 Sampliner RE. Updated guidelines for the diagnosis, surveillance, and therapy of Barrett's esophagus. Am J Gastroenterol 2002; 97: 1888-95.

13 Oberg S, Johansson J, Wenner J, et al. Endoscopic surveillance of columnarlined esophagus: frequency of intestinal metaplasia detection and impact of antireflux surgery. Ann Surg 2001; 234: 619-26.

14 Beck F, Erler T, Russell A, James R. Expression of $\mathrm{Cdx}-2$ in the mouse embryo and placenta: possible role in patterning of the extra-embryonic membranes. Dev Dyn 1995; 204: 219-27.

15 Silberg DG, Sullivan J, Kang E, et al. $\mathrm{Cdx} 2$ ectopic expression induces gastric intestinal metaplasia in transgenic mice. Gastroenterology 2002; 122: 689-96.

16 Silberg DG, Swain GP, Suh ER, Traber PG. Cdx1 and cdx2 expression during intestinal development. Gastroenterology 2000; 119: 961-71.

17 Eda A, Osawa H, Satoh K, et al. Aberrant expression of CDX2 in Barrett's epithelium and inflammatory esophageal mucosa. J Gastroenterol 2003; 38: 14-22.

18 Moons LM, Bax DA, Kuipers EJ, et al. The homeodomain protein CDX2 is an early marker of Barrett's oesophagus. J Clin Pathol 2004; 57: 1063-8.

19 Phillips RW, Frierson Jr HF, Moskaluk CA. Cdx2 as a marker of epithelial intestinal differentiation in the esophagus. Am J Surg Pathol 2003; 27: 1442-7.

20 Houde M, Laprise P, Jean D, et al. Intestinal epithelial cell differentiation involves activation of p38 mitogen-activated protein kinase that regulates the homeobox transcription factor CDX2. J Biol Chem 2001; 276: 21885-94.

21 Yamamoto H, Bai YQ, Yuasa Y. Homeodomain protein $\mathrm{CDX} 2$ regulates gobletspecific MUC2 gene expression. Biochem Biophys Res Commun 2003; 300: 813-8.

22 Groisman GM, Amar M, Meir A. Expression of the intestinal marker $\mathrm{Cdx} 2$ in the columnar-lined esophagus with and without intestinal (Barrett's) metaplasia. Mod Pathol 2004; 17: 1282-8.

23 Steininger H, Pfofe DA, Muller H, HaagSunjic G, Fratianu V. Expression of CDX2 and MUC2 in Barrett's mucosa Pathol Res Pract 2005; 201: 573-7.

24 Corfield AP, Myerscough N, Longman R, et al. Mucins and mucosal protection in the gastrointestinal tract: new prospects for mucins in the pathology of gastrointestinal disease. Gut 2000; 47: 589-94.

25 Bax DA, Haringsma J, Einerhand AW, et al. MUC4 is increased in high grade intraepithelial neoplasia in Barrett's oesophagus and is associated with a proapoptotic Bax to Bcl-2 ratio. J Clin Pathol 2004; 57: 1267-72.
26 Guillem P, Billeret V, Buisine MP, et al. Mucin gene expression and cell differentiation in human normal, premalignant and malignant esophagus. Int $J$ Cancer 2000; 88: 856-61.

27 Warson C, Van De Bovenkamp JH, Korteland-Van Male AM, et al. Barrett's esophagus is characterized by expression of gastric-type mucins (MUC5AC, MUC6) and TFF peptides (TFF1 and TFF2), but the risk of carcinoma development may be indicated by the intestinal-type mucin, MUC2. Hum Pathol 2002; 33: 660-8.

28 Niwa T, Ikehara $\mathrm{Y}$, Nakanishi $\mathrm{H}$, et al. Mixed gastric- and intestinal-type metaplasia is formed by cells with dual intestinal and gastric differentiation. J Histochem Cytochem 2005; 53: 75-85.

29 Shields HM, Rosenberg SJ, Zwas FR, et al. Prospective evaluation of multilayered epithelium in Barrett's esophagus. Am J Gastroenterol 2001; 96: 3268-73.

30 Chandrasoma P. Controversies of the cardiac mucosa and Barrett's oesophagus. Histopathology 2005; 46: 361-73.

31 Hamilton SR, Yardley JH. Regnerative of cardiac type mucosa and acquisition of Barrett mucosa after esophagogastrostomy. Gastroenterology 1977; 72: 669-75.

32 Oberg S, Peters JH, DeMeester TR, et al. Inflammation and specialized intestinal metaplasia of cardiac mucosa is a manifestation of gastroesophageal reflux disease. Ann Surg 1997; 226: 522-30; discussion 530-32.

33 Glickman JN, Shahsafaei A, Odze RD. Mucin core peptide expression can help differentiate Barrett's esophagus from intestinal metaplasia of the stomach. Am J Surg Pathol 2003; 27: 1357-65.

34 Chandrasoma PT, Der R, Dalton P, et al. Distribution and significance of epithelial types in columnar-lined esophagus. Am J Surg Pathol 2001; 25: 1188-93.

35 Cassaro M, Di Mario F, Leandro G, Genta RM, Rugge M. The dark side of the gastric biopsy. Hum Pathol 1999; 30: 741-4.

36 Fitzgerald RC, Omary MB, Triadafilopoulos G. Dynamic effects of acid on Barrett's esophagus. An ex vivo proliferation and differentiation model. J Clin Invest 1996; 98: 2120-8.

37 Kumble S, Omary MB, Fajardo LF, Triadafilopoulos G. Multifocal heterogeneity in villin and Ep-CAM expression in Barrett's esophagus. Int J Cancer 1996; 66: 48-54. 


\section{APPENDIX}

Flow cytometry for the detection of Barrett's patients at risk for developing adenocarcinoma (CYBAR) study group

Centres, departments and investigators:

Erasmus MC/University Medical Centre Rotterdam: Department of Gastroenterology and Hepatology - M. Kerkhof, E.J. Kuipers, J.G. Kusters, P.D. Siersema; Department of Pathology - H. van Dekken; Department of Public Health - E.W. Steyerberg, M. Kruijshaar, M.-L. Essink-Bot.

Ysselland Hospital, Capelle aan den IJssel: Department of Gastroenterology and Hepatology - W.A. Bode, H. Geldof; Department of Pathology - H. van der Valk.

Ikazia Hospital, Rotterdam: Department of Gastroenterology and Hepatology - D.J. Bac, R.J. Th Ouwendijk, C. Leunis; Department of Pathology - R.W.M. Giard.

Free University Medical Centre, Amsterdam: Department of Gastroenterology and Hepatology - E.C. Klinkenberg, H. Akol; Department of Pathology - G.A. Meijer.

Albert Schweitzer Hospital, Dordrecht: Department of Gastroenterology and Hepatology - W. Lesterhuis, R. Beukers, P. Honkoop, W. van de Vrie; Department of Pathology - R.J. Heinhuis.

Deventer Hospital, Deventer: Department of Gastroenterology and Hepatology - F. ter Borg; Department of Pathology - J.W. Arends.
Streekziekenhuis Midden Twente, Hengelo: Department of Gastroenterology and Hepatology - G. Tan; Department of Pathology - J. van Baarlen.

Rijnstate Hospital, Arnhem: Department of Gastroenterology and Hepatology - N. Aparicio, R. de Vries, P. Wahab, P. van Embden; Department of Pathology A.H. Mulder.

Sint Franciscus Gasthuis, Rotterdam: Department of Gastroenterology and Hepatology - L. Berk, A.J.P. van Tilburg, H.S.L.M. Tjen; Department of Pathology - H. van der Valk.

Medisch Spectrum Twente, Enschede: Department of Gastroenterology and Hepatology - J.J. Kolkman, P. Mensink, R. Veenstra; Department of Pathology - J. van Baarlen.

Maasland Hospital, Sittard: Department of Gastroenterology and Hepatology - L. Engels; Department of Pathology - W. Vos.

University Medical Centre, Groningen: Department of Gastroenterology and Hepatology - F.T.M. Peters; Department of Pathology - A. Karrenbeld.

Isala Klinieken, Zwolle: Department of Gastroenterology and Hepatology - M. Oudkerk Pool, B.E. Schenk, J. Kamp, W.H. Bos, F. Veen; Department of Pathology - F. Moll.

De Heel Medical Centre, Zaandam: Department of Gastroenterology and Hepatology - R. Loffeld; Department of Pathology - M.J. Flens.

Franciscus Hospital, Roosendaal: Department of Gastroenterology and Hepatology - H. van Roermund; Department of Pathology - F. Lockefeer. 